\title{
Designing an E-Game Program in Mathematics for 5th Grade Saudi Female Pupils: Does Gagne's Theory Have Any Effectiveness in Developing Their Achievement of Mathematics?
}

\author{
Salma Katib S. AL-Shammari1, Abdellatif E. Elgazzar1,2, Ahmed M. Nouby ${ }^{1,3}$ \\ ${ }^{1}$ Distance Learning Department, CGS, Arabian Gulf University, Manama, Kingdom of Bahrain \\ ${ }^{2}$ Department of Inst. Technology, Women Faculty, Ain Shams University, Cairo, Egypt \\ ${ }^{3}$ Department of Curricula \& Instruction, College of Education, Suez Canal University, Ismailia, Egypt \\ Email: sose777@hotmail.com, dr.a latif@hotmail.com, ahmednouby2005@yahoo.com
}

Received December 2014

\section{Abstract}

Design variables of e-learning technologies have gained great attention and concern from developers as well as researchers. So, e-Games design has gained a special concern in its design as an eLearning technology in accordance with learning theories and instructional models such as Gagne's theory. This research aims at investigating the effectiveness of an instructional e-game program designed according to the Gagne's theory on developing mathematics' achievement among primary school pupils in Saudi Arabia. The research sample composed of 46 female pupils from the fifth grade pupils at King Fahd University of Petroleum and Minerals' primary schools. Thus, the Developmental Research Method was adopted. The study sample was selected as a purposed cluster one of two classes (sections). The quasi-experimental design with pre and post testing was used. The sample was divided to two equal groups which were randomly assigned as: experimental group 1 (e-Games with Gagne's theory), experimental group 2 (e-Games without Gagne's theory); (23) female pupils in each group. An instructional unit has been selected from the 5th grade mathematics curriculum, its content was analyzed to drive the mathematical achievement categories of knowledge and cognitive skills. Then, a list of instructional design standards was derived for designing the instructional e-Games. The two instructional e-games programs were developed by the 1st author using Elgazzar (2002) ISD Model of the 2nd author: one e-Games program with Gagne's theory and the other one e-Games program without Gagne's theory. Both the instructional e-games programs were refereed, revised and approved according to those derived standards of instructional design. A Mathematics Achievement Test was developed and approved to be valid and reliable. The 1st author carried out the research experiment according to the experimental design. So; the first experimental group 1 was taught using the e-Games program (according to Gagne's theory), and the experimental group 2 was taught using e-Games program (without Gagne's theory). The research instrument was implemented pre and post experimentation according to the experimental design. Data were collected and encoded to the SPSS package and ana-lyzed us- 
ing appropriate statistical methods to test the research hypotheses. Research results have revealed that there is no effectiveness of e-Games Program with Gagne's theory as compared with e-Games without Gagne' Theory in developing the Achievement of Mathematics, and this result gives an answer to the main research question that designing instructional e-Games program based on Gagne's Theory doesn't have any comparative Effectiveness in Developing Saudi female pupils' in the Achievement of Mathematics. This result calls for further research on other learning outcomes of Mathematics' learning. The article includes Tables, References, Recommendations, and a list of proposed future researches.

\section{Keywords}

Design, E-Games Program, Based-On Gagne's Theory, Elgazzar (2002) ISD Model, Effectiveness, Mathematics Subject Matter, Achievement in Mathematics, Primary Stage, Saudi Arabia

\section{Introduction}

Educational and training technology as an applied scientific field is being developed due to the research and development in its innovations, increasing knowledge, and concerns to its design variables. The attention has become not only the effect of the use of these innovations on learning outcomes, but extended attention to how to design these innovations and discovering effectiveness of these modern designs. The educational games-in general — have benefits and potentials, and electronic games-in particular-are of those innovations that need more research in their design variables and discovering their effectiveness. The current research is in line with these guidelines in discovering the effectiveness of new design of e-Games according to Gagne's theory in developing achievement in school mathematics.

Din \& Calao [1], in their study, revealed an effectiveness of educational games in mathematics learning and knowledge retention among high school students. Their study and other studies didn't consider any of the many design variables of educational games that should be considered. Basically those design variables are derived from learning/instructional principles, theories, new approaches, innovations, and models. More, recently researchers [2] have given attention to Gagne's nine events of instruction for application in e-Learning to investigate its effectiveness. So, this current research seeks to reveal the effectiveness of the design of educational e-Games in the light of the instructional events of Gagne' theory, as the authors expect that this design for educational e-Games can be of more effect in the development of mathematics education outcomes, such as cognitive achievement.

\section{Guidelines from Gagne's Theory of Learning and Instruction}

Since the late of 1970s and the early of 1980s, Gagne' as an instructional technology Scholar [3]-[5] has proposed an applied theory that combines learning and instruction to instructional designers, that is, instruction is what we do in the learner's environment and as a result learning takes place simultaneously inside the learner's mind [6] [7] Moreover, the instructional situation/experience is the relationship between nine instructional events should be designed in the learner's environment and nine learning events takes place inside the learner's mind. So, if instructional designers design the learner's environment according to these nine instructional events-as guidelines-in any instructional/learning system, intended learning outcomes will be more likely to take place inside the learner's mind as a result. These instructional/learning systems could be educational games' programs, educational e-Games programs, e-learning environments, and e-training environments. In all these types of instructional/learning environments can be designed in view of these guidelines that are derived from Gagne' theory of these nine instructional events. These guidelines can be implemented in designing learning activities that will help learners to acquire cognitive skills and achievement. These nine events of Gagne', which are mentioned here as nine guidelines to give designers more flexibility in their implementation, Gagne' [8] describes that these nine Instruction events can be applied in different ways depending on the different required learning outcomes, these nine instructional events are as follows: gaining attention, knowing learning objectives, retrieve prerequisite learned capabilities, presenting stimulus materials—content, learning guidance, provide 
practice for eliciting the performance, provide feedback, assessing performance, and finally enhancing retention and transfer learning. In view, these nine events can be viewed as we mentioned earlier as guidelines. The second author of this paper has realized the value of these guidelines as early as 1990s and put them in the heart of his ISD model proposed in 1995 for developmental research which was implemented in developing e-Games [6] [9] [10]. It should be known that the authors are using the term "Gagne theory”, “Gagne' instructional events”, and the term "guidelines from Gagne’ theory” in the same sense.

\section{Theoretical Foundations, Designing, and Design Standards of E-Games}

There are some theoretical foundations that are supporting the expecting potential and positive effect of educational games/e-Games on instruction and learning outcomes of mathematics' achievement. Basically, games have some motivational characteristics such as competitions, rewarding, challenges, and eagerness for winning that have potential in developing learning outcomes. Gunter, Kenny\& Vick [11] mentioned that Ganji's Theory of educational electronic games presents three main principles, namely: interest in learning, setting conditions that must be met to achieve success in the games, and events that guide for the development and delivery of units of learning. Disruption of Cognitive Equilibrium Theory of Van Eck [12] [13], in view of this theory as Van Eck believes that the key to learning in electronic games is where the student feels a state of dissatisfaction with the knowledge, and the desire to continue to win, so he starts to try and explore the game to bring awareness, understanding, and finally adapt, then indulge, or immersion in the learning tasks within the game. Van Eck has proposed three approaches to fulfill the potential of e-Games. However, potentials and capabilities of educational e-Games aren't guaranteed without research and development on the design of e-Games in accordance to sound learning/instructional models, such as Guidelines from Gagne' Theory under investigation in this current research.

\section{Design Aspects of Guidelines from Gagne' Theory in E-Games}

Authors set some design aspects of guidelines from Gagne’ Theory in e-Games so as to be considered as bases for developing educational e-Games program. Those design aspects of the nine instructional events are as follows:

1) Gaining the learner's attention is to be at the beginning of the game and through-out the game. Basically, introductory screens, logos, logo of the Ministry of Education, objectives of learning from the game, clear rules of the game, visual and sound effects, multimedia, on-screen display of important events and variable, and avoidance of distractions are all of good attention gaining for e-Games.

2) Informing the learner about learning objectives is very essential design aspect. Several ways are to be considered to inform the learner about learning objectives. These include but not limited to allocating some of the screens at the beginning of the program in general, starting each game with a list of its learning objectives, and clarity of learning objectives' statements, and suitable location of objectives on screen layout.

3) Calling the learner's required previous experience relevant to the learning is essential design aspects to bring meaningful and understandable learning. This can be done through the provision of a range of relevant questions, relevant situations, providing introductory screens at the beginning of each e-Game for the learner to practice required information to be ready for that game, good sequencing of e-Games as well as events within each e-Game, and helping the learner to remember some of the concepts that have already studied and needed for him to achieve his learning objectives while winning the e-Game.

4) Content Display (stimuli), this event can be done in the course of the e-Games sequencing the content as along with the game, equations, algebraic expressions, graphics, good screen layout, texts, sounds, sequencing small questions, and multimedia.

5) Provide guidance and assistance, this event can take different types that may include guidance and help for game controls, giving hints, providing information to help learner not to quit the game. Also, hints and cues to make learner proceeds an win the game and achieve learning objectives.

6) Provide practice for eliciting required performance. This event may be accomplished during playing the e-Game by giving practice to elicit the required responses, giving a sequence of questions and places on the screen for the learner to submit answers, gradual presentation of the questions from the simple ones to the complex ones, from easy ones to difficult ones, providing respond area that appear in the same screen where the question to appear to answer it, diversity of interaction offered by the game for the learner between clicking the 
key, or choose from a drop-down list, or move an item from one place to another in the same screen patterns, or enter text using the keyboard.

7) Provide feedback: This event is to give the student direct feedback after every activity, appropriate feedback as soon as the student response to any question presented during playing the game, varying types of feedback, varying feedback amount from short to long, varying feedback between one medium to multimedia.

8) Assessing performance: This event can be done within the game, between games, or after related games, self-assessment tests, quizzes, formative and summative tests, e-tests, and may be paper answered tests. These assessing performance tools are given to learner during the e-Game to monitor accomplishing objectives and mastering learning.

9) Enhancing retention and transfer of learning: This event can through providing concept maps, diagrams of information after segments of games, giving practices to apply learning, assignments, providing summaries, using colored texts, highlighting texts, stressing important points, and providing more applications to what is learned.

Those Design Aspects of Guidelines from Gagne’ Theory’s works as a flexible framework for designing educational e-Games with Gagne’ Theory.

\section{ISD Model for E-Games Program with/out Gagne's Theory Designs}

Instructional Systems are dynamic, interactive, interrelated components of learning resources (people, materials, content, devices, facilities, techniques to achieve pre-specified instructional objectives. Instructional Systems Development is the application of systems' development procedures (Analysis, Design, Develop/Produce, Evaluate, Utilize, Feedback, and Revise) of instructional systems [14]. Basically, ISD models guide instructional developers in the instructional developmental process that vary in their purposes, amount of detail provided, degree of linearity in which they are applied, and their operational tools [15]. Authors reviewed available ISD models that can be implement in this our developmental research that can accommodate Gagne' theory about nine instructional events and their discussed design aspect of them in developing e-Games program with/out Gagne' theory (WGT/WoutGT). Elgazzar (2002) ISD model [9] [10] [14] was selected for this task because, as it has been mentioned, has Gagne' nine instructional events in the heart of its design phase (see Figure 1). This model's procedures and implementation is found in several developmental researches [16]. The model as it is shown in Figure 1 has five interrelated phases: Analysis, Design, Production/ construction, Evaluation, Use, and Feedback. It should be seen that the step, Designing the instructional events (Gagne) and elements of the learning process, is in the design phase of that model.

\section{Research Problem and Questions}

The research problem has been stated as "there is an urgent need to get an e-learning solutions as e-Games to meet decline in students' achievement and to discover the answer of the question: Does Gagne's Theory have any Effectiveness in Developing their Achievement of Mathematics?" and a main research question was to be answered: is the design of e-games according to Gagne's theory (WGT) effective in developing achievement among primary school pupils in mathematics? Four sub-questions have been derived:

1) What are the content components for students to achieve from a selected unit from primary school mathematics?

2) What are the design standards of e-Games program to development of achievement in mathematics?

3) What are the WGT and WoutGT designs of e-Games programs according those standards using Elgazzar ISD model (2002) to develop students achievement?

4) How effective is the implementation of these two designs WGT and WoutGT of e-games in developing achievement?

\section{Research Method}

The Developmental Research Method as described [15] was used in this research. This research method combined three integrated research methods were used:

1) Descriptive research method implemented in students' characteristic analysis, course content analysis, resources analysis, and establishing design standards list of the e-Games designs, 


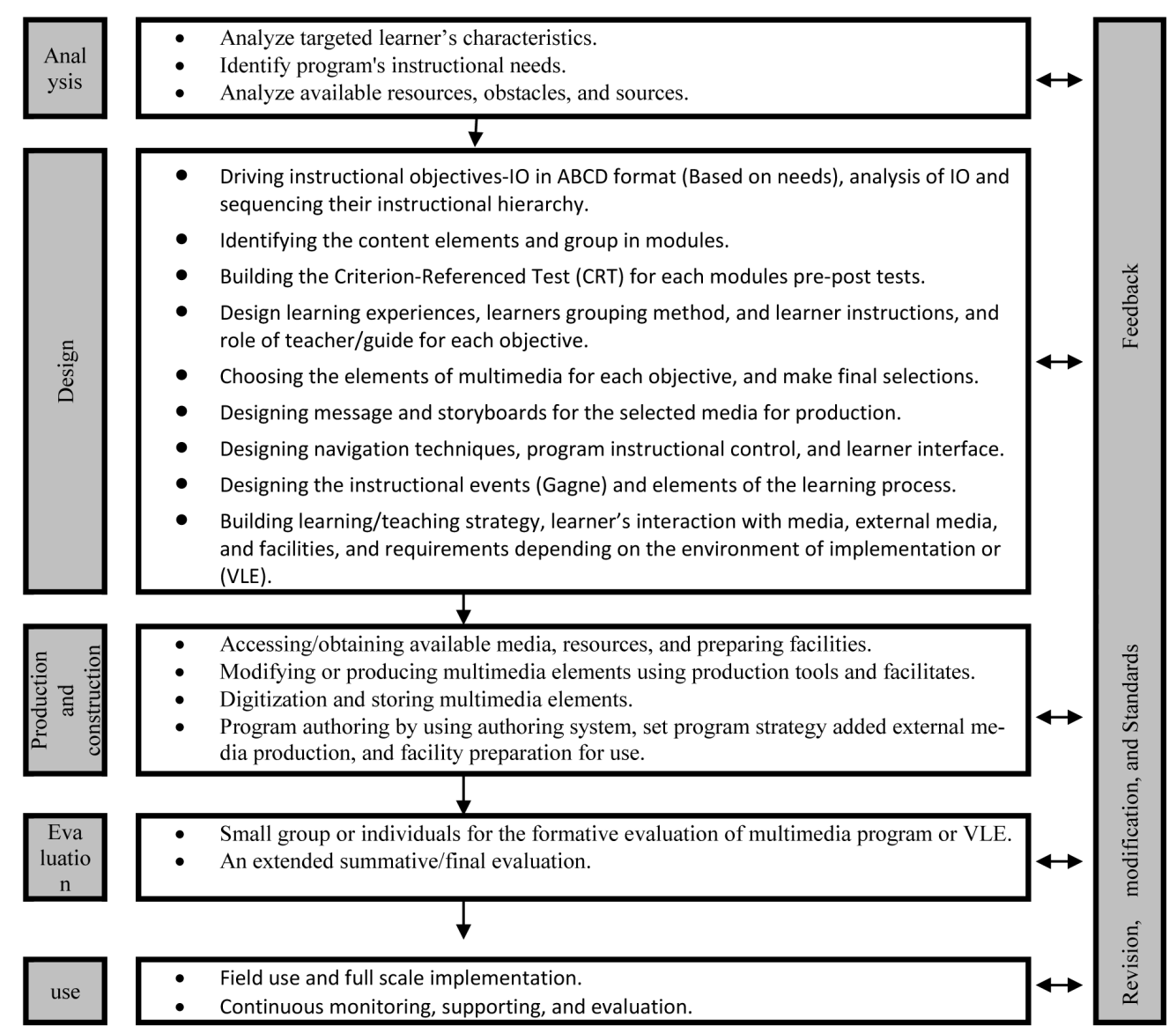

Figure 1. Elgazzar (2002) ISD model [9,10,14] for e-Games Program development WGT/WoutGT.

2) Systems Development Method in terms of implementing Elgazzar ISD Model $[9,10,14]$ in developing the two designs of e-Games WGT and WoutGT, and

3) Experimental research method in the research experiment to investigate the comparative effects of the two designs WGT and WoutGT of e-Games on students' mathematics achievement.

\section{Research Procedures}

\subsection{Content Analysis of "Algebraic Expressions and Equations" Unit}

Researchers started with conducting content analysis of the "Algebraic Expressions and Equations” Unit of primary school mathematics as it is required to Elgazzar ISD model (2002). This unit contains eight lessons. The content analysis component of achievement was refereed and was used to derive instructional needs, instructional objectives, and the cognitive achievement test. So, the first sub-question has been answered.

\subsection{Developing E-Games Program Instructional Design Standards}

Based on extensive literature reviews, eLearning standards, and e-games designs, Guidelines from Gagne’s theory of Learning and Instruction, Design Aspects of Guidelines from Gagne' Theory in e-Games, analyses of learning content in (1), and phases of Elgazzar ISD Model a list of instructional design standards were derived and was subjected for refereeing from experts. The final most agreed upon list of standards and their indicators became (10) standards and (77) of their indicators. So, the second sub-question has been answered.

\subsection{Developing the WGT and WoutGT E-Games Program Designs}

The Elgazzar (2002) ISD model was selected for developing the two treatment programs of e-Games as it was 
mentioned earlier. A very lengthy details of developmental tasks were done on applying Elgazzar ISD Model (2002) in Figure 1 until the two the WGT and WoutGT e-Games Program Designs approved by the list of ISD design standards. These detailed developmental tasks have been described in Alshammari [17]. The phases of the ISD model were applied by the 1st author till the formative evaluation and the approval of the two designs of e-Games program were meeting the ISD design standards. Then the two put on the virtual learning environment (VLE) of moodle and on CDs. So, the third sub-question has been answered and the two designs were ready to be implemented in research experiment.

\subsection{Participants and Experimental Design}

Research sample of this research was a purposive clustered sample. It was consisted of (46) of female pupils from two classes from 5th grade in one elementary schools, Khobar Governorate, KSA. This sample was divided randomly into two groups of (23) pupils each. The two experimental groups with pretest-posttest Quasi-Experimental Design was used with pre-post tests. So, pretest and posttest of achievement of mathematics was to be applied on the two groups.

\subsection{Research Tool: Test of Achievement of Mathematics (TAM)}

Authors developed a Test of Achievement of Mathematics (TAM) as the research tools of this research. The test was built on learning objectives and was consisted of (24) items in the form of varied forms of objective test items on mathematics components of achievement of from analyses in (1). TAM validity was done by specialists in the field of educational technology and mathematics education. The reliability of the test carried out on its pretest data, the calculated Cronbach's Alpha $(\alpha)$ coefficient was $(\alpha=0.82)$. This value has confirmed the reliability of the achievement test of mathematics. So, it is shown that the test is valid and reliable test for the purpose of this research.

\subsection{Experiment of the Research}

The 1st author carried out the implementation of the two e-Games program designs: WGT and WoutGT during the 1st semester of the year 2013-2014 according to the experimental design. Pupils enjoyed studying from the two treatments. The process of studying the e-Games programs was guided by the 1st author. The experiment lasted about one month. Group one studied using the educational e-Games WGT program while the other group studied using the educational e-Games WoutGT design. Pretest and posttest of the achievement of mathematics were implemented. Data was collected and coded to SPSS Package.

\section{Results and Discussions}

Researchers applied descriptive statistics procedures using SPSS statistical procedures to compute means and standard deviations for the two e-Games program designs: WGT design and WoutGT design as in Table 1. It is so clear from data that the mean score of WGT is (23.39) design which isn't better than WoutGT (24.57) design in the posttest of TAM. However, in the mean of gain scores of TAM of WoutGT is higher than WGT (17.13 $>15.13)$. These noticeable differences are not expected, WGT isn't better than WoutGT. However, these differences among means might not be significant. On the other hand, both designs are effective on developing TAM as noticeable when comparing between means of pretests' scores and their posttests' scores.

Table 1. Means and standard deviations for the two e-Games program designs of research variables.

\begin{tabular}{ccccc}
\hline & \multicolumn{5}{c}{ e-Games program designs } \\
\cline { 2 - 5 } Research variables & \multicolumn{3}{c}{ WGT design (23) } & \multicolumn{2}{c}{ WoutGT design (23) } \\
\cline { 2 - 5 } & M & SD & M & 3.67 \\
\hline Posttest of TAM & 23.39 & 5.09 & 24.57 & 3.00 \\
Pretest of TAM & 8.26 & 5.30 & 7.43 & 4.88 \\
Gain of TAM & 15.13 & 5.01 & 17.13 & \\
\hline
\end{tabular}


To answer the fourth sub-question, tow hypotheses were formulated tested as follows.

Hypothesis (1): There are significant differences at level $(\alpha \leq 0.05)$ between the two means the WGT design and WoutGT design of e-Games in posttest and gain scores of TAM for the WGT design.

To test this hypothesis, the independent samples t-test was applied to test the significance of the differences between means of the posttest scores an gain in TAM scores. So for the posttest scores in Table 2, the t-value (0.90) of the two means' difference of TAM $(23.39,24.57)$ at df $(44)$ is not significant at $(0.05)$ since the computed significance $(0.37>0.05)$. Also, the t-value $(1.36)$ of the two means' difference of gain of TAM $(15.13$, $17.13)$ at $\mathrm{df}(44)$ is not significant at $(0.05)$ since the computed significance $(0.81>0.05)$, so, the null hypothesis is not rejected. So, Hypothesis (1) is rejected to mean that the differences among the means' scores in posttest and gain of TAM between the educational e-Games' designs: WGT and WoutGT are not significant.

To make sure that there may be a significant difference between the two e-Games designs' means of posttest of TAM isn't due to differences in both pretests of TAM, another Hypothesis (2) was formulated and tested to check the difference between posttest of TAM when pretests' scores of TAM are controlled.

Hypothesis (2): There is a significant difference at level $(\alpha \leq 0.05)$ between the two means of the WGT design and WoutGT design of e-Games in posttest when controlling the pretest scores.

Researchers applied one-way ANCOVA to test Hypothesis (2). Table 3 shows results of this test. From Table 3 , the F-value (1.39) of the main effect of between e-Games' designs (WGT, WoutGT) at df $(1,43)$ is not significant at $(0.05)$ since the computed significance $(0.25>0.05)$, so, Hypothesis (2) is rejected for the variance for TAM.

These results revealed that both WGT e-Games design and WoutGT design weren't effective even after controlling the effects of the pretests' scores of TAM as covariates in the ANCOVA model. This clearly shows that designing educational e-Games with Gagne's Theory doesn't have any comparative Effectiveness in Developing 5th Grade Saudi Female Pupils Achievement of Mathematics. These important results raise the issue that there may be another factors that are being involved in TAM other than designing e-Games WGT such as students characteristics and the content nature and characteristics of mathematics. When dependent t-tests were applied to test significance of the observed differences between pretests of TAM and posttest of TAM in both e-Games designs, t-tests showed the that these difference were significant at the at level $(\alpha \leq 0.05)$. This really means that both e-Games designs are equally effective on developing achievement of mathematics of Saudi female 5th grade pupils.

\section{Research Recommendations}

Based on these findings of the research, the following practical recommendations can be driven:

Table 2. Independent t-tests results of the means' differences between WGT and WoutGT of post-tests scores and gain scores of TAM.

\begin{tabular}{|c|c|c|c|c|c|c|c|}
\hline Test scores & Group & $\mathbf{N}$ & Mean & SD & $\mathbf{t}$ & $\underline{\text { df }}$ & significance \\
\hline \multirow[t]{2}{*}{ Posttest TAM } & WGT & 23 & 23.39 & 5.09 & 0.90 & 44 & 0.37 \\
\hline & WoutGT & 23 & 24.57 & 3.67 & & & \\
\hline \multirow{2}{*}{ Gain of TAM } & WGT & 23 & 15.13 & 5.10 & 1.36 & 44 & 0.81 \\
\hline & WoutGT & 23 & 17.13 & 4.88 & & & \\
\hline
\end{tabular}

Table 3. One-way ANCOVA results of posttest of TAM with pretest of TAM as covariate.

\begin{tabular}{cccccc}
\hline Source of Variance & SS & df & MSS & F & significance \\
\hline Pretest of TAM & 104.48 & 1 & 104.48 & 5.91 & 0.02 \\
e-Games designs & 24.60 & 1 & 24.60 & 1.39 & 0.25 \\
Error & 760.65 & 43 & 17.69 & & \\
Total & 27329.00 & 46 & & & \\
\hline
\end{tabular}


1) These two developed educational e-Games designs: WGT and WoutGT should be used in improving mathematics learning in $5^{\text {th }}$ grade in Elementary School mathematics curriculum in public and private education.

2) The list of instructional design standards of educational e-Games which developed in this research should be adopted by researchers and e-Learning. developers in e-Learning and distance learning centers.

3) The instructional design model of Elgazzar (2002) should be used in developing e-Games and other e-Learning resources in direction of Gagne’ Theory of instructional events.

\section{Future Researches}

The following future researches are suggested:

1) Studying the effects of designing educational e-Games with Gagne' Theory on developing higher cognitive skills such as problem solving skills.

2) A fellow-up of the effects of designing educational e-Games with Gagne' Theory on developing mathematical thinking, curiosity, and creative imagination among elementary stage pupils.

3) Using developmental research method in as defined by Elgazzar [14] in research of educational technology, e-Learning, and distance learning.

4) Studying the effects of the interaction between these two e-Games' designs and cognitive styles on developing achievement of mathematics and mathematical problem solving.

\section{Acknowledgements}

This research has been done as a part of King Hamad Academic Chair of eLearning activities, Distance Learning Dept., Arabian Gulf University. The authors are deeply giving special thanks to Arabian Gulf University for supporting them to attend the CITE 2015. Special thanks go also to CITE 2015 for honoring Elgazzar-the second author-Chairing the CITE 2015 Conference session, Shanghai, China.

\section{References}

[1] Din, F. and Calao, J. (2001) The Effects of Playing Educational Video Games on Kindergarten Achievement. Child Study Journal, 31, 95-102. http://eric.ed.gov/?id=EJ643651

[2] Pinfan, Z. and Stmant, K. (2010) Application of Robert Gagne’s Nine Events of Instruction to the Teaching of Website Localization. Journal of Technical Writing \& Communication, 40, 337-362. http://dx.doi.org/10.2190/TW.40.3.f

[3] Gagné, R.M. (1977) The Conditions of Learning. 3rd Edition, Holt, Rinehart, and Winston, New York.

[4] Gagné, R.M. (1969) Learning and Communication. In: Wiman, R.V. and Meierhenry, W.C., Eds., Educational Media: Theory and Practice, Charles E. Merrill pub. Company, Columbus.

[5] Gagné, R.M. and Briggs, L.J. (1979) Principles of Instructional Design. 2nd Edition, Holt. Rinehart, and Winston, New York.

[6] El-Gazzar, A.-L. E. (1995) An Exploratory Study of Using an ISD Model in Instructional Technology among Female Student Teachers, Faculty of Education, United Arab Emirates University. Journal of Instructional Technology, Egyptian Association of Educational Technology, 5, 1-2. (ARABIC).

[7] El-Gazzar, A.E. (2001) Instructional Technology: Theory and Practice. Cairo: Ed. Tech. and Information Unit, Women Faculty, Ain-Shams University. (ARABIC).

[8] Gagne, R. (1988) Mastery Learning and Instructional Design. Performance Improvement Quarterly, 1, 7-18. http://dx.doi.org/10.1111/j.1937-8327.1988.tb00003.x

[9] Elgazzar, A.E. (2010) Research Directions in Standards of Designing Environment for Applying Information Communications and Technology (ICT) in Instruction and Training. The First International Symposium: ICT Applications in Instruction and Training, Faculty of Education, King Saud University, Riyadh, KSA, April 12-14 2010. (ARABIC).

[10] El-Gazzar, A.-L. E. (2002) Effectiveness of Using Multimedia Computer Assisted Instruction on Acquisition of Some Levels of Learning of Scientific Concepts According to Frayer's Model of Concepts' Evaluation. Journal of Education, Scientific Refereed Journal, Faculty of Education, Al-Azhar University, Cairo, No. (155), 37-83. (ARABIC).

[11] Gunter, G., Kenny, R. and Vick, E. (2007) Taking Educational Games Seriously: Using the Retain Model to Design Endogenous Fantasy into Standalone Educational Games. Educational Technology Research and Development, 55, 511-532. 
[12] Van Eck, R. (2006) Building Intelligent Learning. In: Gibson, D., Aldrich, C. and Prensky, M., Eds., Games and Simulations in Online Learning: Research \& Development Frameworks, Idea Group, Hershey. http://dx.doi.org/10.4018/978-1-59904-304-3.ch014

[13] Van Eck, R. (2001) Promoting Transfer of Mathematics Skills through the Use of a Computer-Based Instructional Simulation Games and Advisement. 6th Annual Mid-South Instructional Technology Conference, Murfreesboro, TN.

[14] Elgazzar, A.E. (2014) Developing E-Learning Environments for Field Practitioners and Developmental Researchers: A Third Revision of an ISD Model to Meet E-Learning and Distance Learning Innovations. Open Journal of Social Sciences, 2, 29-37. http://dx.doi.org/10.4236/iss.2014.22005

[15] Gustafson, K.L. and Branch, R.M. (1997) Survey of Instructional Development Models. 3rd Edition, ERIC Clearinghouse on Information and Technology, Syracuse, New York.

[16] Altaaban, M.A., Elgazzar, A.E., and Eldeeb, A.A.K. (2013) Linear Design vs. Branched Design of Digital Storytelling in a Web Based Distance Learning Course: Does It Have Effects on Students’ Knowledge Acquisition and Creativity Thinking Skills? Journal of Teaching and Education, 2, 383-400. http://universitypublications.net/jte/0203/pdf/V3NA281.pdf

[17] Al-Shammari, S.K. (2014) Designing an E-Game Program Based on Gagne’ Theory and Its Effectiveness in Developing Saudi Female Pupils' Mathematics Thinking and Achievement. M.A. Thesis, Arabian Gulf University. 